\title{
PKM BUDIDAYA LELE SEBAGAI ALTERNATIF MATA PENCAHARIAN PETANI SAWAH TADAH HUJAN DI DESA JUKONG
}

\author{
Wiwin Widiasih'), Siti Muhimatul Khoiroh $^{2),}$ Handy Febri Satoto ${ }^{3)}$, Agung Prasetyo ${ }^{4),}$ \\ Prastyo Eka Yunianto ${ }^{5}$ \\ ${ }^{1,2}$ Program Studi Teknik Industri, Fakultas Teknik, Universitas 17 Agustus 1945 Surabaya \\ Email: ${ }^{1}$ wiwin_w@untag-sby.ac.id, ${ }^{2}$ muhimatulsiti@gmail.com
}

\begin{abstract}
Abstrak
Kelompok Tani Sawah Tadah Hujan Desa Jukong beranggotakan kurang lebih lima belas orang petani. Kelompok Tani ini memiliki alamat di Balai Desa Jukong dan dikelola langsung oleh Ibu Sekretaris Kepala Desa, yaitu Ibu Uswatun. Pada saat musim hujan, petani menanam jagung atau padi pada sawah yang dimilikinya. Namun pada musim kemarau petani-petani menjadi kuli bangunan di Surabaya. Hal tersebut dapat meningkatkan urbanisasi dan dapat menyebabkan menurunnya perekonomian masyarakat desa Jukong serta dapat meningkatkan pengangguran. Solusi yang ditawarkan adalah membuat/pengadaan kolam untuk budidaya lele dengan diameter $3 \mathrm{~m}$ dan ketinggian 1,2m; pengadaan bibit lele sebanyak 700 ekor; pengadaan $80 \mathrm{~kg}$ pakan lele sampai dengan dipanen; pelatihan keterampilan langkah-langkah budidaya lele yang efektif; pelatihan dan pendampingan pengelolaan usaha serta pengelolaan keuangan. Metode yang digunakan adalah identifikasi permasalahan yang mendesak untuk segera diatasi; metode partisipatif dalam pelatihan dan pendampingan; monitoring dan evaluasi terhadap hasil PKM dengan indikator budidaya lele dapat meningkatkan pendapatan kelompok tani sawah tadah hujan; keberlanjutan program dengan tim pelaksana sebagai fasilitator dilakukan dalam bentuk konsultasi, diskusi, dan pendampingan strategis.
\end{abstract}

Kata kunci: Petani sawah tadah hujan, Budidaya lele, Manajemen keuangan, Jukong, PKM

\begin{abstract}
The Rainfed Farmer Farmer Group consists of approximately fifteen farmers. This Farmer Group has an address at the Jukong Village Hall and is managed directly by the Secretary of the Village Head, Mrs. Uswatun. During the rainy season, farmers grow corn or rice in their fields. But in the dry season, farmers become construction workers in Surabaya. This can increase urbanization and can cause a decline in the economy of the Jukong village community and can increase unemployment. The solution offered is making / procuring ponds for catfish cultivation with a diameter of $3 \mathrm{~m}$ and a height of $1.2 \mathrm{~m}$; procurement of 700 catfish seeds; procurement of $80 \mathrm{~kg}$ of catfish feed until harvest; training of effective catfish cultivation steps; training and assistance in business management and financial management. The method used is the identification of urgent problems to be immediately addressed; participatory methods in training and mentoring; monitoring and evaluation of the results of PKM with indicators of catfish cultivation can increase the income of rainfed rice farmer groups; program sustainability with the implementation team as facilitators is carried out in the form of consultations, discussions and strategic assistance.
\end{abstract}

Keywords: rainfed lowland rice farmers, catfish cultivation, financial management, jukong, PKM 


\section{PENDAHULUAN}

Pertanian tadah hujan adalah sebuah usaha pertanian yang memanfaatkan air hujan sebagai sumber air utama. Tingkat produktivitas pertanian tadah hujan secara umum dinilai rendah dikarenakan beberapa sebab antara lain kondisi tanah yang terdegradasi, tingginya evaporasi, kekeringan, banjir, dan minimnya manajemen air. Sawah tadah hujan dapat didefinisikan sebagai sawah yang sistem pengairannya sangat mengandalkan curah hujan. Jenis sawah ini hanya menghasilkan di musim hujan. Di musim kering sawah ini dibiarkan tidak diolah karena air sulit didapat atau tidak ada sama sekali (Utoyo, 2007). Sawah tadah hujan hanya dapat dipanen setahun sekali (Yani and Rahmat, 2007).

Masyarakat Desa Jukong, Kec. Labang, Kab. Bangkalan kebanyakan berprofesi sebagai petani sawah tadah hujan. Kelompok Tani Sawah Tadah Hujan Desa Jukong beranggotakan kurang lebih 15 orang petani. Kelompok Tani ini memiliki alamat di Balai Desa Jukong dan dikelola langsung oleh Ibu Sekretaris Kepala Desa, yaitu Ibu Uswatun.

Pada saat musim hujan, petani menanam jagung atau padi pada sawah yang dimilikinya. Namun pada musim kemarau petani-petani tersebut kebanyakan berprofesi sebagai kuli bangunan di Surabaya. Hal tersebut dapat meningkatkan urbanisasi dan semakin menurunnya perekonomian masyarakat desa Jukong dikarenakan adanya biaya transportasi dari Madura ke Surabaya. Bila hal ini terus berlanjut maka perekonomian masyarakat desa Jukong dapat menurun dan meningkatnya pengangguran.

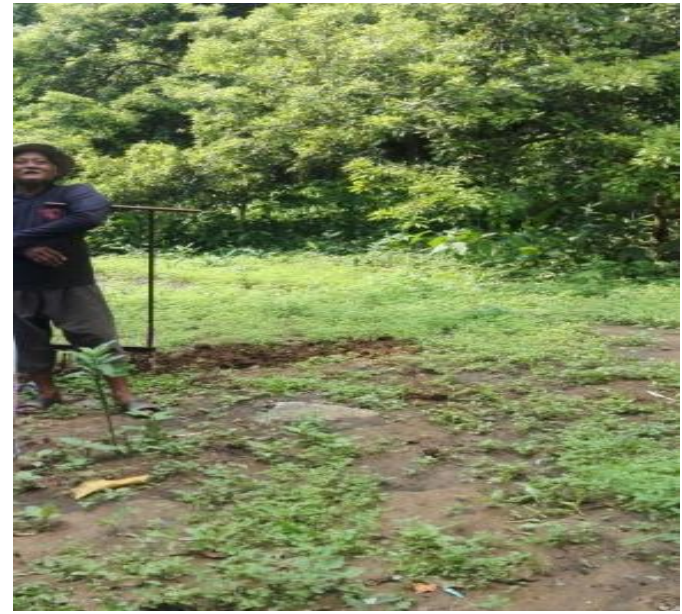

Gambar 1 Sawah Tadah Hujan

Sebagian besar petani tadah hujan adalah sebagai kepala keluarga yang memiliki jumlah tanggungan yaitu rata-rata lima orang tanggungan. Tingkat Pendidikan masyarakat desa Jukong rata-rata berpendidikan tamatan SD atau SMP. Sebagian besar pendapatan kepala keluarga di bawah rata-rata UMR yaitu sebesar Rp.1.500.000. Diperlukan adanya alternatif mata pencaharian baru untuk masyarakat petani desa Jukong pada saat tidak musim tanam dengan pekerjaan yang relatif mudah. Hal ini dikarenakan tingkat Pendidikan masyarakatnya yang rendah dan dapat meningkatkan perekonomian petani sawah tadah hujan desa Jukong.

Budidaya ikan lele adalah suatu kegiatan dimana orang memelihara ikan lele untuk kemudian dijual. Ikan lele merupakan jenis ikan yang relatif mudah dibudidayakan di perairan iklim hangat. Ikan lele dapat dibudidayakan di beberapa lokasi seperti di kolam, tangki, maupun sungai kecil. Budidaya ikan lele sangat diminati para peternak lele karena pasarnya yang terus berkembang.

Ketinggian air yang ideal untuk budidaya ikan lele adalah 100-120 cm. Pengisian kolam dilakukan secara bertahap. Setelah kolam dipupuk, diisi air sampai batas $30-40 \mathrm{~cm}$. Ikan lele bisa dipanen setelah mencapai ukuran 9-12 ekor per kg. Ukuran sebesar itu bisa dicapai dalam tempo 2,5-3,5 bulan dari benih berukuran $5-7 \mathrm{~cm}$. Vitamin 
B-12 yang terkandung dalam ikan lele juga sangat tinggi, satu ekornya mengandung 40 persen vitamin B-12, yang bermanfaat untuk memecah zat makanan menjadi energi. Kandungan zat di dalam ikan lele juga sangat rendah merkuri. Asam lemak omega juga terkandung dalam ikan lele, jumlahnya sekitar $875 \mathrm{mg}$ asam lemak omega-6 dan lemak omega-3 sekitar $220 \mathrm{mg}$. Kedua asam lemak tersebut sangat dibutuhkan manusia dalam sehari untuk menjaga kesehatan fungsi jantung.

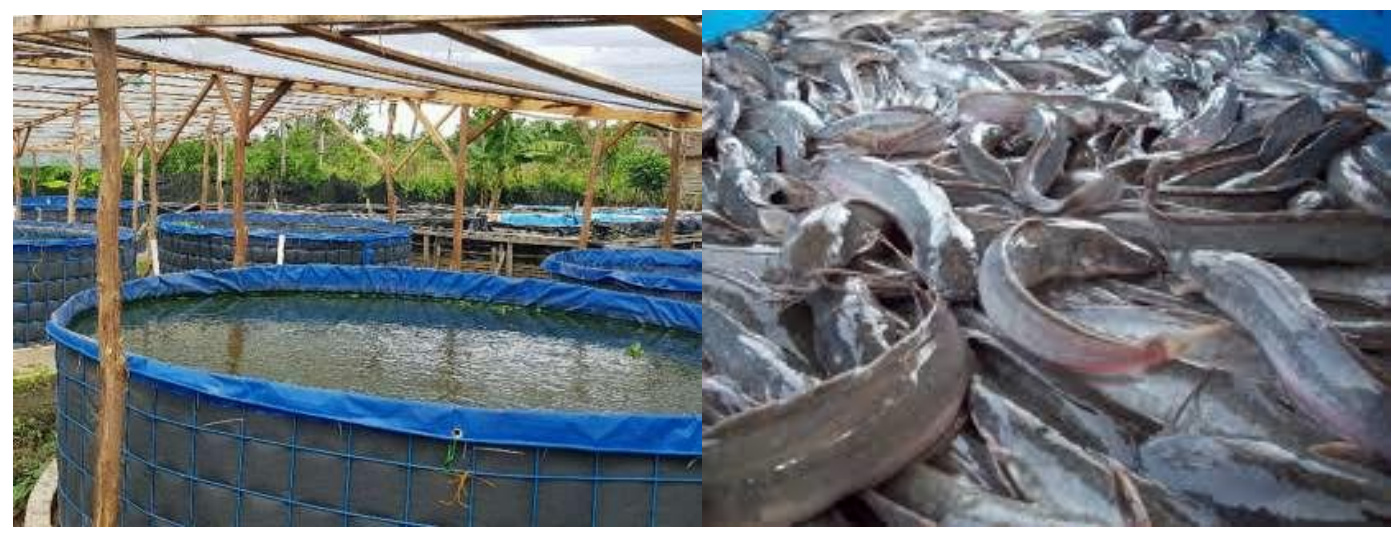

Gambar 2 Budidaya Ikan Lele

Dari hasil pengamatan, budidaya ikan lele adalah alternatif mata pencaharian bagi kelompok tani sawah tadah hujan desa Jukong pada saat tidak musim tanam. Budidaya lele cukup mudah dilakukan bagi pemula dan menghasilkan pendapatan tambahan bagi kelompok tani sawah tadah hujan desa Jukong. Kelompok tani sawah tadah hujan desa Jukong ini juga belum melaksanakan manajemen usaha yang baik, bahkan pengelolaan keuangan (pembukuan sederhana) belum dilakukan dengan baik. Diharapkan dengan manajemen usaha yang baik didapatkan aspek-aspek yang perlu diperbaiki dan ditingkatkan. Menurut (Widiasih, Murnawan and Industri, 2016) menyatakan bahwa suatu badan usaha beraktivitas produksi bertujun untuk mencapai profit semaksimal mungkin dengan biaya produksi yang seminimal mungkin.

Pengelolaan keuangan menjadi salah satu masalah yang seringkali terabaikan oleh para pelaku bisnis usaha mikro, khususnya berkaitan dengan penerapan kaidah-kaidah pengelolaan keuangan dan akuntansi yang benar. Masalah ini biasanya timbul dikarenakan pengetahuan dan informasi pelaku usaha mikro mengenai akuntansi sangat terbatas, latar belakang pendidikan para pelaku usaha mikro juga mempengaruhi pengetahuan para pelaku usaha mikro.

Dalam akuntansi, economic entity concept merupakan konsep yang sangat ideal untuk usaha mikro, karena dengan menggunakan konsep ini usaha mikro akan mengetahui laba operasional usaha yang sebenarnya. Dengan penerapan tersebut usaha mikro ini juga membuat laporan keuangan meskipun secara sederhana. Manfaat yang dirasakan usaha mikro adalah memudahkan usahanya ketika ingin mengembangkan usahanya melalui pinjaman pada pihak lain (Risnaningsih, 2017). Adanya laporan keuangan atau pembukuan akuntansi akan memberikan beberapa manfaat bagi pelaku UMKM, antara lain (Junaidi, 2017):

1. UMKM dapat mengetahui, memilah, dan membedakan antara keuangan usaha dan keuangan pemilik;

2. UMKM dapat mengetahui posisi arus kas baik sumber maupun penggunaannya;

3. UMKM dapat mengetahui aliran uang tunai selama periode tertentu

Manajamen keuangan sederhana perlu untuk dilakukan agar pencatatan aliran kas 
masuk dan keluar tercatat. Hal ini dilakukan agar petani dapat mengetahui, memonitor, dan mengevaluasi pendapatan dan pengeluaran dari usaha bertani dan penjualan ikan hasil budidaya lele.

Berdasarkan kondisi eksisting yang telah disampaikan dapat dirumuskan permasalahan mitra antara lain:

1. Diperlukan adanya alternatif mata pencaharian baru untuk masyarakat petani desa Jukong pada saat tidak musim tanam dengan pekerjaan yang relatif mudah. Hal ini dikarenakan tingkat Pendidikan masyarakatnya yang rendah dan dapat meningkatkan perekonomian petani sawah tadah hujan desa Jukong.

2. Kelompok kelompok tani sawah tadah hujan desa Jukong ini juga belum melaksanakan manajemen usaha yang baik, bahkan pengelolaan keuangan (pembukuan sederhana) belum dilakukan dengan baik. Diharapkan dengan manajemen usaha yang baik didapatkan aspek-aspek yang perlu diperbaiki dan ditingkatkan.

Dengan adanya PKM ini memiliki tujuan antara lain:

1. Sebagai alternatif mata pencaharian kelompok tani tadah hujan saat musim kemarau.

2. Membantu petani mendapat penghasilan tambahan.

3. Mewujudkan inovasi warga khususnya di bidang peternakan.

\section{METODE PELAKSANAAN}

Berdasarkan permasalahan yang dihadapi oleh mitra dan solusi yang dapat ditawarkan, maka metode pelaksanaannya adalah sebagai berikut:
1. Melakukan identifikasi permasalahan yang dihadapi oleh mitra Kelompok Tani Sawah Tadah Hujan melalui metode survei awal, wawancara dengan mitra, dan observasi lapangan.

2. Berdasarkan hasil identifikasi permasalahan yang dihadapi, selanjutnya ditentukan beberapa masalah yang mendesak yang harus segera diatasi diantaranya:

a) Tersedianya kolam untuk budidaya lele dengan ukuran diameter $3 \mathrm{~m}$ dengan ketinggian $1,2 \mathrm{~m}$.

b) Tersedianya bibit lele sebanyak 700 ekor lele

c) Tersedianya pakan lele sampai dengan dipanen $( \pm 3$ bulan $)$ sebanyak $80 \mathrm{~kg}$ pellet

3. Pelatihan ketrampilan budidaya lele dengan mengadakan penyuluhan langkahlangkah budidaya lele yang efektif

4. Pelatihan ketrampilan Pelatihan Ketrampilan Pembukuan Sederhana dan pengelolaan keuangan usaha.

5. Metode Partisipatif yang diterapkan dalam proses pelatihan dan pendampingan ini adalah keterlibatan para kelompok tani sawah tadah hujan secara langsung dalam aplikasinya.

6. Dilakukan monitoring dan evaluasi terhadap hasil PKM ini dengan indikator proses produksi budidaya lele yang dapat meningkatkan pendapatan kelompok tani sawah tadah hujan desa Jukong.

7. Melakukan keberlanjutan program dengan Tim pelaksana sebagai fasilitator bila terjadi masalah setelah program PKM berjalan pada aspek produksi dan manajemen. Hal ini dilakukan agar peningkatan kualitas budidaya lele dan manajemen berkelanjutan sehingga dapat meningkatkan kesejahteraan masyarakat. 
Tabel 1 Peran Tim Pengusul dan Mitra dalam Program PKM

\begin{tabular}{|c|c|c|c|c|}
\hline \multirow[t]{2}{*}{ No } & \multirow[t]{2}{*}{ Kegiatan } & \multicolumn{2}{|c|}{ Peran Aktif dalam Kegiatan } & \multirow{2}{*}{$\begin{array}{l}\text { Indikator } \\
\text { Capaian }\end{array}$} \\
\hline & & Tim PKM & Mitra & \\
\hline 1 & $\begin{array}{l}\text { Koordinasi dan } \\
\text { sosialisasi program }\end{array}$ & $\begin{array}{l}\text { - Pembagian tugas } \\
\text { - Sebagai } \\
\text { pelaksanaa program }\end{array}$ & $\begin{array}{l}\text { Fasilitator } \\
\text { pelaksanaan program }\end{array}$ & $\begin{array}{l}\text { Kesepakatan rencana } \\
\text { kegiatan dan bentuk } \\
\text { partisipasi mitra }\end{array}$ \\
\hline 2 & $\begin{array}{l}\text { Pengadaan kolam untuk } \\
\text { budidaya lele dengan } \\
\text { diameter } 3 \text { meter dan } \\
\text { ketinggian } 1,2 \text { meter. }\end{array}$ & $\begin{array}{l}\text { Perancang dan } \\
\text { penyedia kolam } \\
\text { budidaya lele }\end{array}$ & $\begin{array}{l}\text { Ikut terlibat dalam } \\
\text { perancangan kolam } \\
\text { budidaya lele }\end{array}$ & $\begin{array}{l}\text { Tersedianya kolam } \\
\text { budidaya lele dengan } \\
\text { diameter } 3 \text { meter dan } \\
\text { ketinggian } 1,2 \text { meter. }\end{array}$ \\
\hline 3 & $\begin{array}{l}\text { Pengadaan bibit lele } \\
\text { sebanyak } 700 \text { ekor lele }\end{array}$ & $\begin{array}{l}\text { Penyedia bibit lele } \\
\text { sebanyak } 700 \text { ekor } \\
\text { lele }\end{array}$ & $\begin{array}{l}\text { Ikut terlibat dalam } \\
\text { pembelian bibit lele }\end{array}$ & $\begin{array}{l}\text { Tersedianya bibit lele } \\
\text { sebanyak } 700 \text { ekor lele }\end{array}$ \\
\hline 4 & $\begin{array}{l}\text { Pengadaan pakan lele } \\
\text { sampai dengan dipanen } \\
\text { ( } \pm 3 \text { bulan) sebanyak } 80 \\
\text { kg pellet }\end{array}$ & Penyedia pakan lele & $\begin{array}{l}\text { Ikut terlibat dalam } \\
\text { pembelian pakan lele }\end{array}$ & $\begin{array}{l}\text { Tersedianya pakan lele } \\
\text { sampai dengan dipanen } \\
( \pm 3 \text { bulan) sebanyak } 80 \\
\text { kg pellet }\end{array}$ \\
\hline 5 & $\begin{array}{l}\text { Pelatihan ketrampilan } \\
\text { penyuluhan langkah- } \\
\text { langkah budidaya lele } \\
\text { yang efektif }\end{array}$ & Sebagai narasumber & $\begin{array}{l}\text { - Sebagai peserta } \\
\text { pelatihan } \\
\text { - Penyedia sarana } \\
\text { dan prasarana } \\
\text { pelatihan }\end{array}$ & $\begin{array}{l}\text { Meningkatnya } \\
\text { ketrampilan mitra dalam } \\
\text { budidaya lele yang } \\
\text { efektif }\end{array}$ \\
\hline 6 & $\begin{array}{l}\text { Pelatihan dan } \\
\text { pendampingan } \\
\text { manajemen usaha dan } \\
\text { pengelolaan keuangan }\end{array}$ & $\begin{array}{l}\text { Sebagai pendamping } \\
\text { dan konsultan } \\
\text { kegiatan }\end{array}$ & $\begin{array}{l}\text { Sebagai pelaku } \\
\text { aplikasi manajemen } \\
\text { usaha dan } \\
\text { pengelolaan } \\
\text { keuangan }\end{array}$ & $\begin{array}{l}\text { Meningkatnya } \\
\text { kemampuan } \\
\text { pengelolaan usaha } \\
\text { dengan tersedianya } \\
\text { pembukuan dan } \\
\text { pencatatan kegiatan } \\
\text { usaha secara teratur. }\end{array}$ \\
\hline 7 & $\begin{array}{l}\text { Penyerahan kolam lele, } \\
\text { bibit lele, dan pakan lele } \\
\text { ke mitra }\end{array}$ & $\begin{array}{l}\text { Penyerahan kolam } \\
\text { lele, bibit lele, dan } \\
\text { pakan lele }\end{array}$ & $\begin{array}{l}\text { Fasilitator } \\
\text { pelaksanaan program }\end{array}$ & $\begin{array}{l}\text { kolam lele, bibit lele, } \\
\text { dan pakan lele } \\
\text { digunakan mitra dan } \\
\text { berita acara serah terima }\end{array}$ \\
\hline 8 & $\begin{array}{l}\text { Monev (monitoring dan } \\
\text { evaluasi) }\end{array}$ & $\begin{array}{l}\text { Pemonitor dan } \\
\text { evaluator }\end{array}$ & $\begin{array}{l}\text { - Sumber data dan } \\
\text { informasi } \\
\text { - Ikut aktif dalam } \\
\text { forum pembahasan } \\
\text { monev }\end{array}$ & $\begin{array}{l}\text { Tidak ada hambatan } \\
\text { yang berarti }\end{array}$ \\
\hline 9 & Pembuatan Laporan & $\begin{array}{l}\text { Penyusun laporan } \\
\text { dan artikel ilmiah }\end{array}$ & $\begin{array}{l}\text { Sumber data dan } \\
\text { informasi }\end{array}$ & $\begin{array}{l}\text { Laporan PKM dan } \\
\text { Jurnal Nasional } \\
\text { Pengabdian Masyarakat } \\
\text { ber-ISSN }\end{array}$ \\
\hline 10 & Keberlanjutan Program & $\begin{array}{l}\text { - Memberi saran dan } \\
\text { masukan } \\
\text { - Sebagai pemberi } \\
\text { solusi bila terjadi } \\
\text { masalah }\end{array}$ & $\begin{array}{l}\text { Bertanya pada tim } \\
\text { pelaksana bila terjadi } \\
\text { masalah }\end{array}$ & $\begin{array}{l}\text { Mitra semakin paham } \\
\text { dan mahir dalam } \\
\text { peningkatan budidaya } \\
\text { lele dan manajemennya }\end{array}$ \\
\hline
\end{tabular}

\section{HASIL DAN PEMBAHASAN}

Berdasarkan permasalahan yang dihadapi mitra Kelompok Tani Sawah Tadah Hujan
Desa Jukong, pengusul program PKM bersama mitra sepakat untuk mengatasi permasalahan dengan cara sebagai berikut: 
1. Membuat/pengadaan kolam untuk budidaya lele dengan ukuran diameter 3 meter dengan ketinggian 1,2 meter.

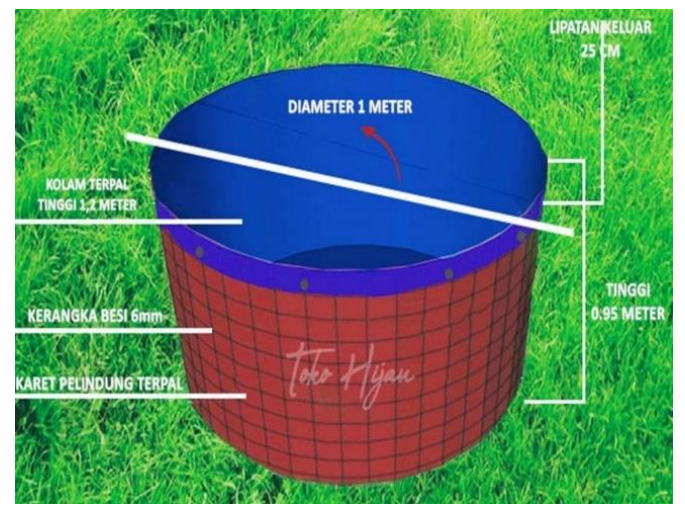

Gambar 3. Kolam untuk budidaya lele dengan diameter 3 meter dan ketinggian 1,2 meter

2. Pengadaan bibit lele sebanyak 700 ekor lele.

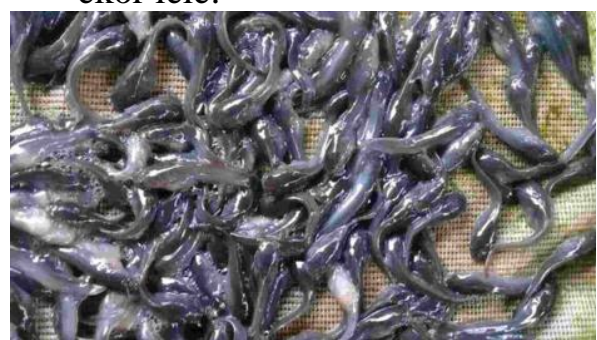

Gambar 4 Pengadaan bibit lele sebanyak 700 ekor lele

3. Pengadaan pakan lele sampai dengan dipanen ( \pm 3 bulan) sebanyak $80 \mathrm{~kg}$ pellet.

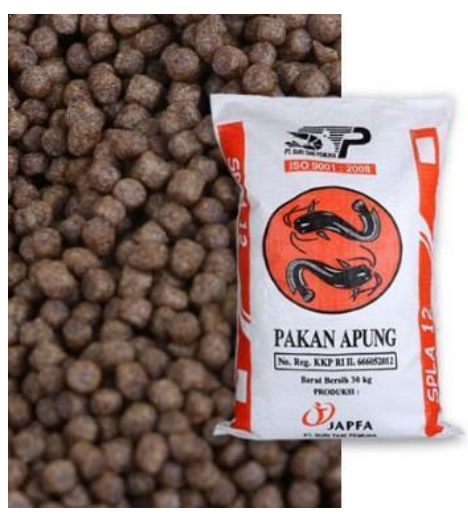

Gambar 5 Pengadaan pakan lele sampai dengan dipanen ( \pm 3 bulan) sebanyak $80 \mathrm{~kg}$ pellet

4. Pengadaan alat jarring untuk menangkap dan memindahkan ikan lele dari dan ke kolam yang telah dipartisi beberapa bagian.

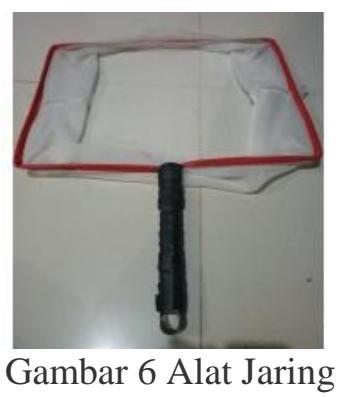

5. Peningkatan ketrampilan budidaya lele, dengan mengadakan pelatihan keterampilan langkah-langkah budidaya lele yang efektif

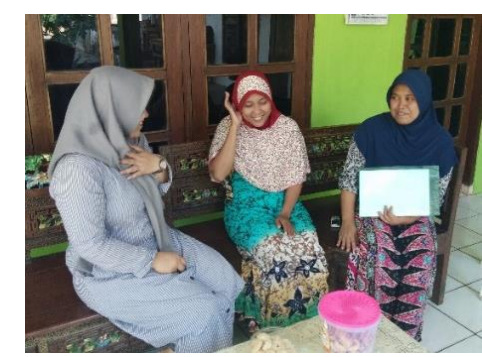

Gambar 7 Diskusi untuk Pelatihan Keterampilan Budidaya Lele

6. Untuk meningkatkan manajemen pengelolaan dan keuangan usaha serta mengatasi kelemahan pengelolaan usaha, pengusul PKM mengadakan pelatihan dan pendampingan pengelolaan usaha, dan pengelolaan keuangan.

Pada kesempatan pelaksanaan kegiatan PKM budidaya lele sebagai alternatif mata pencaharian petani sawah tadah hujan di musim kemarau Desa Jukong, Kecamatan Labang, Kabupaten Bangkalan dilakukan diskusi dan pembahasan mengenai morfologi desain produk yaitu kolam lele. Analisis morfologi adalah sebuah pendekatan yang 
sistematis dan terstruktur untuk mencari alternatif penyelesaian dengan menggunakan matriks sederhana. Analisis morfologi ini dibuat sebagai pertimbangan dan pengambilan keputusan yang sistematis untuk memilih komponen dan mekanisme pembuatan kolam lele yang optimal dan ergonomis.

Tabel 2 Perancangan Kolam Budidaya

\begin{tabular}{|c|c|c|c|}
\hline No. & Perancangan & Kebutuhan Perancangan & Penyusunan Konsep \\
\hline 1. & Kolam lele & $\begin{array}{l}\text { a. Kerangka kolam yang kokoh } \\
\text { b. Tempat yang mudah dibersihkan } \\
\text { c. Jumlah partisi kolam } \\
\text { d. Volume air dalam kolam }\end{array}$ & $\begin{array}{l}\text { Kerangka kolam dibuat dengan } \\
\text { menggunakan kerangka besi } \\
\text { Material yang digunakan yaitu } \\
\text { terpal yang mudah dibersihkan } \\
\text { dan dipilihkan bahan terpal yang } \\
\text { berkualitas baik } \\
\text { Jumlah partisi minimal adalah } \\
\text { tiga bagian bertujuan untuk } \\
\text { pemindahan lele } \\
\text { 1. Volume air dalam kolam diisi } \\
\text { 100-120 sentimeter } \\
\text { 2. Terdapat katup/keran untuk } \\
\text { pembuangan air pada saat } \\
\text { pembersihan kolam }\end{array}$ \\
\hline 2. & Benih lele & $\begin{array}{l}\text { a. Pemilihan benih lele } \\
\text { b. Pengelolaan benih lele }\end{array}$ & $\begin{array}{l}\text { Benih yang sehat dan lincah } \\
\text { serta tidak ada cacat } \\
\text { Ukuran benih lele 5-7 sentimeter } \\
\text { 1. Sebelum benih lele ditebar } \\
\text { perlu penyesuaian iklim /suhu } \\
\text { maka perlu diletakkan dalam } \\
\text { wadah/tong selama } 15 \text { menit } \\
\text { 2. Memiringkan wadah/tong dan } \\
\text { membiarkan benih untuk } \\
\text { keluar dengan sendirinya ke } \\
\text { kolam lele yang telah } \\
\text { disiapkan } \\
\text { 3. Menebar benih sekitar 200- } \\
\text { 400 ekor per meter persegi } \\
\text { 4. Pemberian pakan lele perlu } \\
\text { diatur agar tidak terlalu } \\
\text { banyak/sering dan tidak } \\
\text { kterlalu sedikit/jareng } \\
\text { 5. Pemberian pakan lele lebih } \\
\text { optimal sore hari karena lele } \\
\text { hewan nocturnal (aktif di } \\
\text { malam hari) } \\
\text { 6. Pengelolaan air kualitas dan } \\
\text { kuantitas perlu dijaga } \\
\text { 7. Pembersihan kolam minimal } \\
\text { seminggu sekali } \\
\text { 8. Perlu pemisahan ukuran lele } \\
\text { agar yang kecil tidak dimakan } \\
\text { yang besar } \\
\text { 9. Pengendalian hama dan }\end{array}$ \\
\hline
\end{tabular}




\begin{tabular}{|c|l|l|l|}
\hline No. & Perancangan & \multicolumn{1}{|c|}{ Kebutuhan Perancangan } & \multicolumn{1}{|c|}{ Penyusunan Konsep } \\
\hline & & \multicolumn{1}{|c|}{ penyakit perlu diperhatikan } \\
\hline 3. & Alat pendukung & $\begin{array}{l}\text { a. Mudah didapat } \\
\text { b. Murah harganya } \\
\text { c. Material yang kokoh dan berkualitas } \\
\text { baik }\end{array}$ & $\begin{array}{l}\text { Alat jaring ikan } \\
\text { Pegangan alat jaring terbuat dari } \\
\text { tongkat sehingga kuat }\end{array}$ \\
\hline
\end{tabular}

\section{KESIMPULAN}

Pada kegiatan PKM yang telah dilaksanakan pada bulan Juli-Agustus 2019 ini dapat ditarik kesimpulan antara lain:

1. Telah dilakukan identifikasi masalah dan solusi untuk menyelesaikan permasalahan warga Desa Jukong, Kecamatan Labang, Kabupaten Bangkalan sesuai dengna metodologi pelaksanaan yang dilakukan yaitu membuat kolam untuk budidaya ikan lele.

2. Setelah dilakukan pengadaan kolam lele beserta perlengkapannya, juga dilakukan pelatihan/sosialisasi terkait hal teknis dan prosedur dalam melakukan budidaya ikan lele di Desa Jukong, Kecamatan Labang, Kabupaten Bangkalan agar dapat meningkatkan produktivitas lele.

3. Untuk meningkatkan keterampilan dan kompetensi dalam mengelola budidaya ikan lele warga Desa Jukong, Kecamatan Labang, Kabupaten Bangkalan telah dilakukan pelatihan manajemen keuangan dengan bentuk pembuatan pembukuan keuangan yang sederhana.

4. Program keberlanjutan di masa akan datang yaitu dilakukan konsultasi dan pembimbingan strategis terkait permasalahan yang muncul dan evaluasi atas program PKM yang telah dijalankan.

\section{REFERENSI}

Junaidi (2017) 'Pelatihan Manajemen Keuangan sebagai Upaya Peningkatan Daya Saing UMKM dalam Menghadapi MEA di Kecamatan Tomoni Kabupaten Luwu Timur', Resona Jurnal Ilmiah Pengabdian Masyarakat, 1(1), pp. 4651.

Risnaningsih (2017) 'Pengelolaan Keuangan Usaha Mikro dengan Economic Entity Concept. Jurnal Analisa Akuntansi dan Perpajakan', 1(1), pp. 41-50.

Utoyo, B. (2007) Geografi: Membuka Cakrawala Dunia. Jakarta: PT. Grafindo Media Pratama.

Widiasih, W., Murnawan, H. and Industri, T. (2016) 'Penyusunan Konsep untuk Perancangan Produk Pot Portable dengan Pendekatan Quality Function Deployment ( QFD )', (2012), pp. 3-4.

Yani, A. and Rahmat, M. (2007) Geografi: Menyingkap Fenomena Geosfer. Jakarta: PT. Grafindo Media Pratama. 